\title{
Comparative Analysis of Methodological Trends in the Management of Software Projects: Identification of the Main Variables
}

\author{
Nelson MORENO, Fernando SALAZAR, Sandra DELGADO
}

\begin{abstract}
Nowadays, there are many methodological proposals that support the various aspects of software development projects. In general terms, there are two big identifiable trends: traditional and agile. In the first instance, traditional methods are those characterized by privileging detailed planning work to ensure the quality of the final product. On the other hand, agile methodologies put prediction aside and open a space to changes in planning. This article presents the results obtained from the application of a comparative analysis to 12 methodologies for software projects management, and from 149 software development companies surveyed, leading to identify, from a theoretical - experimental model, the variables that generate the greatest impact on the success of this type of projects. The importance of studying this topic resided in the impact that the correct application of a management methodology has on the results of a project and thus on its success. Regardless of the methodology used, they all propose a series of common processes, considered good practices, which allow achieving the outlined goals.
\end{abstract}

Keywords: agile; key variables; methodology; project management; success; traditional; trend

\section{INTRODUCTION}

When analyzing the existing organizational context, it can be seen that the strategic plans become reality based on projects, and that these are executed thanks to the work and commitment of the collaborators who support the day to day of the companies. This is how the need to develop a closer relationship between companies and their workers arises, in order to have a clear alignment with the established vision, goals and results. Human talent becomes the differentiating factor for many companies and, therefore, must respond to the strategies, adapting to the needs of the market in an effective way [1].

For the specific case of software projects, there is an intensive use of various technologies that allow the development of the products, processes or services that are the object of each of the projects. In many cases, if there is no sufficient technological knowledge, the project cannot be executed, which means abandoning the objectives that have been planned [2].

Baccarini [3] presents the success of software projects from the differentiation of two main concepts: project management in the first instance, for which success is achieved by the achievement of scope, time and cost; and on the other hand, the quality of the expected product, which marks the success, if the customer's expectations are met against the results that are obtained.

For Linberg [4], it is important to control some elements that help increase the probability of success of a software project, such as effective leadership, a favourable organizational climate, the identification of realistic technological requirements, realistic time estimation, and the availability of resources and synergy among the project team.

There are numerous methodological proposals aimed at supporting the different dimensions of software development projects. First of all, we can mention those methodologies with a greater tradition that focus especially on the control of the process, rigorously establishing the activities that are involved, the artefacts that must be produced, and the tools that will be used. Moreover, a new trend that is focused on agile methodologies can be found, which focuses on the human factor and the software product, giving greater value to the individual, to the collaboration with the client, and to the incremental development of software with very short iterations [5].

In both approaches, traditional or agile, it is possible to identify a representative group of methodologies that have been more accepted by software developing companies and therefore have proved to be effective and necessary in a great number of projects, being the references of the best practices in the discipline of project management worldwide.

In that spirit, a good practice can be defined as that successful experience that lasts in time, and that responds to the needs of a particular context. Among the characteristics that differentiate them, we can mention their easy understanding and adaptation, in addition to their adjustment and continuous improvement. In the discipline of project management, good practices have been identified and documented in the form of methodologies, which have gradually gained recognition in the business environment [6].

For this research, 12 methodological reference frameworks were selected: six traditional and six agile, in order to identify the common variables that can serve as a reference point to explain the success of software projects. The following is a general description of each one of them:

\subsection{Traditional Methodological Reference Frameworks}

- $\quad$ PRINCE2 $®$ : established in 1989 by the CCTA as a structured method for effective project management. It is a standard that is used by the UK government and widely recognized and used in the private sector. The most relevant characteristics that tell this methodology apart are: emphasis on product development, control over the project environment since it must adapt to the environment in which it is developed, reduction of uncertainty and control over project risks, it is predictive and is part of a project plan [7].

- CMMI ${ }^{\circledR}$ - Capability Maturity Model Integration: it is a set of good practices that help organizations improve their processes of development and maintenance of products and services. The most relevant characteristics that distinguish this methodology are: emphasis on the 
assurance of product quality through the maturity of business processes, it is focused on software development and is part of the continuous improvement process of the organization, it is predictive and is part of a project plan [8].

- PMBOK $\AA$ - Project Management Body of Knowledge: it is a project management standard developed by the Project Management Institute. It comprises two major sections, the first one on the processes and the context of a project, the second one on the specific areas of knowledge for managing a project. The most relevant characteristics that mark off this methodological reference framework are: emphasis on the management of the processes that are required for project management, control over the project life cycle, it is predictive and part of a project plan, it integrates the project with the company, and is flexible to adapt to the needs of the enterprises [9].

- ISO 21500®: it presents guidelines for project management and direction, and intends to be a reference framework for this discipline. The most relevant characteristics that distinguish this methodology are: it emphasizes on standardizing the processes that are required to properly manage a project, accurately aligns with the PMBOK, it is predictive and is part of a project plan [10].

- ICB - IPMA Competence Baseline: it is the standard of competence for project management that was published by the International Project Management Association (IPMA). The most relevant characteristics that differentiate this methodology are: emphasis on the competencies that the leader must have to guarantee project success: organizational, technical and contextual; it is predictive and part of a project plan [11].

- CCPM - Critical Chain Project Management: oriented to improve the management of projects based on the theory of restrictions proposed by Eliyahu Goldratt. The main postulate that is exposed in this theory is that the performance of projects depends directly on the behaviour of the constraints existing in its activities. The most relevant characteristics that distinguish this methodology are: emphasis on the control of project restrictions, profile management of resources executing the project, uncertainty reduction, it is predictive, it is part of a project plan and focuses on the control of the activities that make up the critical path of the project [12].

\subsection{Agile Methodological Reference Frameworks}

- SCRUM: created by Ikujiro Nonaka and Hirotaka Takeuchi in the 1980s. This new approach is appropriate for developing products in unstable environments with a high degree of flexibility and speed in the delivery of results. The most relevant characteristics that tell this methodology apart are: customer focus, self-directed and self-organized teams, development of iterative and incremental software, specific definition of roles, periodic advance and feedback meetings, time allocation for the development of deliverables [13].

- XP - Extreme Programming: designed by Kent Beck in 1999. The success of the project lies in customer satisfaction and the developers must be able to respond to the changing requirements of the project. The most relevant features that mark off this methodology are: iterative and incremental development, continuous unit tests, greater integration between the programmer and the client, correction of errors before including a new functionality, code simplicity [14].

- DSDM - Dynamic Systems Development Method: created in the 1990 s by a group of software developers who, based on their experience, wanted to join the best practices to obtain a project management methodology that was adaptable to the context in which they performed. The most relevant characteristics that distinguish this methodology are: teamwork of developers and users, the development team can make decisions, development is iterative and incremental, short but frequent deliveries which must be functional, and permanent quality control throughout the life cycle of the project [15].

- ASD - Adaptive Software Development: it is a software development methodology designed by Jim Highsmith and Sam Bayer in the early 1990s. Its approach is to adapt the development process to the permanent changes that occur throughout the life cycle of the project. The most relevant features that differentiate this methodology are: it is iterative and incremental, oriented to the software components not to the tasks, it is tolerant to changes, guided by risks and speculation, the revision of the components serves to learn from errors and to restart the development cycle [16].

- FDD - Feature Driven Development: created by Jeff de Luca and Peter Coad in the year 2000. This working framework, like other agile models, focuses on short iterations and incremental development. The most relevant characteristics that distinguish this methodology are: it emphasizes the design and construction phases, it includes constant monitoring of the project, proposes to have closure stages every two weeks, periodic and tangible results are obtained, it is iterative and incremental [5].

- LSD - Lean software development: designed by Mary Poppendieck and Tom Poppendieck in 2003. The authors took the traditional principles of the LEAN philosophy, initially conceived under a production approach, into the areas of software development. The most relevant characteristics that identify this methodology are: satisfying the client is the highest priority, success depends on the active participation of the client, each project is a team effort, everything can be changed [17].

As Aubry [18] asserts, software development methodologies become a decisive factor in achieving the success of a project. Independent from the methodology that is used, all of them propose a series of common processes, which are good practices to achieve the objectives of the project. Choosing an inadequate methodology or poor application can lead to nonsuccessful projects.

In this way, we decided to undertake this research work in order to carry out a comparative analysis that would allow establishing the common elements among the different project management methodologies, catalogued as the best practices worldwide, and from this result, determine the key variables that impact on the success of software projects executed in the Colombian context. 


\section{METHODOLOGICAL DESIGN}

This research work has been developed under a mixed scheme with a quantitative, deductive, hypothetical and correlational scope. The first part develops an interpretative work on different bibliographic sources to qualitatively determine the common elements among the 12 software development methodologies that were selected, a key input in the design of the suggested theoretical model.

Subsequently and based on the theoretical model that was formulated, we established the research hypotheses, which are intended to describe the success of a software project based on the relation between the selected variables. The following are the planned assumptions:

H1. Software projects that are able to align their objectives with the organizational strategy of the client's company are more likely to succeed.

$\mathrm{H} 2$. The performance of the project team is decisive in the achievement of the objectives that are set for a software project.

H3. Properly managing the risks of a software project increases its probability of success.

H4. Software projects that rely on lessons learned in the past are more likely to be successful.

H5. Properly managing the scope, time, and costs of a software project will positively impact its success.

Finally, we designed and applied a measurement instrument to a sample of 149 Colombian software developers, small and medium-sized. From the collected information, an analysis of correlation of variables was carried out, allowing the validation of the hypotheses. Based on the results that were obtained, the conclusions of the study were written.

\section{ANALYSIS AND DISCUSSION OF RESULTS}

The following are the results that were obtained in each of the phases proposed for this research: interpretative analysis, theoretical model proposal and analysis of correlation and validation of hypotheses.

\subsection{INTERPRETATIVE ANALYSIS}

This section is intended to define three basic concepts that support this research: project, project management and successful project.

A project can be defined as the search for an intelligent solution to the approach of a problem that tends to solve a human need. Projects arise in response to a necessity; they may be focused on solving a problem or allowing an organization to seize an opportunity. A project aims at satisfying an individual or a community with its result. Launching a new product, implementing a strategy or implementing a new technology are some examples of what can be considered as a project [19].

In that order of ideas, for a project to be considered successful, the expectations of the client must be satisfied in its final result. Undoubtedly, projects within organizations generate value to the extent that these expectations are met. All the actions that are taken in an organization must be oriented to generate wellness to its clients [20]. Fortune and White [21] reviewed 63 projects and grouped critical success factors in categories:

- Goals and objectives: they must be realistic, clear and achievable.

- Performance monitoring: effective monitoring and control must be carried out throughout the project.

- Decision markers: unrestricted support from top management, as well as the skills and experience of the project manager are required.

- Transformations: profile of the project team and level of integration of the people that comprise it.

- Communication: good communication and feedback.

- Environment: political stability, environmental influences, previous experiences, organizational culture, adaptability.

- Limit: project size, complexity, duration, number of people involved.

- Resources: budget, technology, training, provision.

- Continuity: risk management, client involvement, different points of view, sponsors, change management.

As it can be seen in this classification, same as with products and markets, projects have a clearly defined life cycle; identifying it helps to understand the activities that must be performed in each of the stages, as well as the level of effort that is required in each of them. The life cycle of a project defines the phases to be executed from the beginning to the end of the project. Splitting the projects into phases allows them to be controlled in an easier way. Generally, in the scope of projects, there are four stages that are recognized and that frame this life cycle: beginning, planning, execution and closure [22].

On the other hand, Project Management is defined as the application of knowledge, skills, tools and techniques to the activities related to the project in order to meet project requirements [9]. Starting from this concept, we can identify four competences that trace the behaviour of the project manager: a person with leadership, capable of making good decisions, focused on results and with a great technical skill that allows him or her to work under pressure.

Besides that, software development methodologies become a decisive factor in achieving the success of a project. Independently of the methodology that is used, all of them propose a series of common processes, which are good practices to achieve the objectives of the project. The choice of an inadequate methodology or poor implementation may lead to a non-successful project [18].

Thus, we decided to compare a representative group of methodologies, between traditional and agile, that have had the broadest acceptance on the part of software developers and therefore have proven effective in a large number of projects. Among the selected methodologies, we can find:

- Traditional methodological reference frameworks: PRINCE 2, CMMI, PMBOK, ISO 21500, IPMA ICB, CCPM.

- Agile methodological reference frameworks: SCRUM, XP, ASD, DSDM, FDD, Lean Software Development.

In this way, a comparative analysis between these methodologies was made and the common variables were 
identified, based on the approach given by each author, as a starting point to propose the theoretical model of this research work.

\subsection{Proposed Theoretical Model}

After the revisions of the selected methodologies, the factors that are proposed in each of them were compared in order to determine the existing coincidences and to build a theoretical model to describe the success of a project. Tab. 1 presents the variables that were singled out as a result of this analysis process.

Table 1Variables selected as a result of the analysis process

\begin{tabular}{|c|c|c|c|}
\hline Variable & Definition & Traditional & Agile \\
\hline Strategy & $\begin{array}{l}\text { It is the level of alignment } \\
\text { between the project and the } \\
\text { organizational strategy of } \\
\text { the client company. How } \\
\text { do the project results } \\
\text { generate customer value? } \\
\text { [23]. }\end{array}$ & $\begin{array}{l}\text { PRINCE2 } \\
\text { CMMI } \\
\text { PMBOK } \\
\text { ISO 21500 } \\
\text { ICB } \\
\text { CCPM }\end{array}$ & $\begin{array}{l}\text { SCRUM } \\
\text { XP } \\
\text { LSD }\end{array}$ \\
\hline Risk & $\begin{array}{l}\text { It is the probability of } \\
\text { occurrence of a setback that } \\
\text { can affect the project by } \\
\text { diverting it from its initial } \\
\text { planning [24]. }\end{array}$ & $\begin{array}{l}\text { PRINCE2 } \\
\text { CMMI } \\
\text { PMBOK } \\
\text { ISO 21500 } \\
\text { ICB } \\
\text { CCPM }\end{array}$ & $\begin{array}{l}\text { FDD } \\
\text { LSD }\end{array}$ \\
\hline Knowledge & $\begin{array}{l}\text { It is the level of } \\
\text { appropriation and } \\
\text { capitalization of the lessons } \\
\text { learned in past projects to } \\
\text { be applied in future } \\
\text { projects [25]. }\end{array}$ & $\begin{array}{l}\text { PRINCE2 } \\
\text { CMMI } \\
\text { PMBOK }\end{array}$ & LSD \\
\hline $\begin{array}{l}\text { Project } \\
\text { Team }\end{array}$ & $\begin{array}{l}\text { It is the group of people } \\
\text { with the required technical } \\
\text { and business skills, who } \\
\text { participate in the planning } \\
\text { and execution of the project } \\
\text { [7]. }\end{array}$ & $\begin{array}{l}\text { PRINCE2 } \\
\text { PMBOK } \\
\text { ISO 21500 } \\
\text { ICB } \\
\text { CCPM }\end{array}$ & $\begin{array}{l}\text { SCRUM } \\
\text { XP } \\
\text { DSDM } \\
\text { ASD } \\
\text { FDD }\end{array}$ \\
\hline Planning & $\begin{array}{l}\text { It is the process by which } \\
\text { the scope and objectives of } \\
\text { the project are defined, and } \\
\text { from these two premises } \\
\text { the necessary resources for } \\
\text { its execution [26]. }\end{array}$ & $\begin{array}{l}\text { PRINCE2 } \\
\text { CMMI } \\
\text { PMBOK } \\
\text { ISO 21500 } \\
\text { ICB } \\
\text { CCPM }\end{array}$ & $\begin{array}{l}\text { SCRUM } \\
\text { XP } \\
\text { DSDM }\end{array}$ \\
\hline
\end{tabular}

Prepared by the authors - compilation of information from the authors consulted

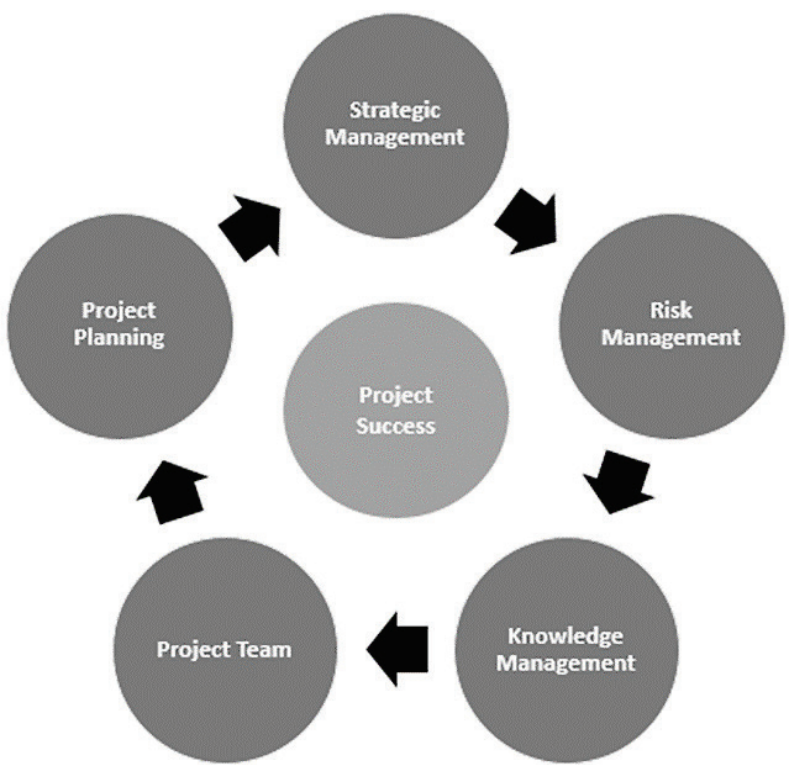

Figure 1 Theoretical model proposed from the relation between the selected variables
As shown in the table above, the group of variables that was selected is largely referred to by the methodological reference frameworks under study, which constitutes strong theoretical evidence of the influence they exert on the success of a software project. Fig. 1 (Prepared by the authors) presents, in a graphical way, the theoretical model that is proposed from the relation between the selected variables.

\subsection{Correlation Analysis and Hypothesis Validation}

The main objective of this stage is to validate, from the statistical point of view, the variables that are established in the theoretical model. To achieve this, a correlation analysis was applied on the information collected in the 149 software companies surveyed, which validated the proposed hypotheses. The following are the results that were obtained:

\subsubsection{Relation between the Strategic Objectives of the Client and Project Success}

Research Hypothesis:

- H1. Software projects that manage to alienate their objectives with the organizational strategy of the client company are more likely to succeed.

- H0. Software projects that manage to alienate their objectives with the organizational strategy of the client company are NO more likely to terminate successfully.

Relation between variables:

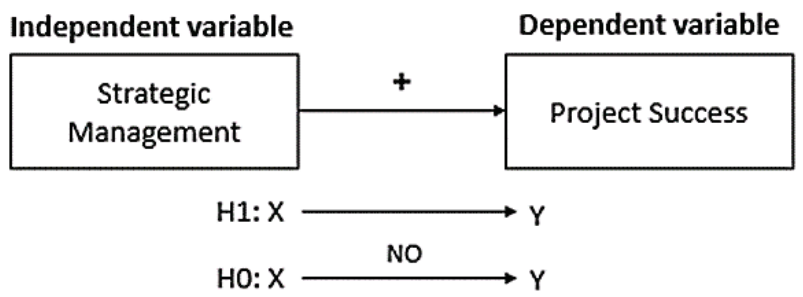

Figure 2 Strategic Management and Project Success (Prepared by the authors)

Results obtained:

Using the SPSS software, data regressions were applied to the values that were obtained, based on the factorial analysis employed with the data that was collected in the survey for the variables of Strategic Management and Project Success. For the purpose of validating or rejecting the null hypothesis, the results obtained for the correlation coefficient, the $\mathrm{p}$ value and the established level of significance will be taken into account.

$p$ value: 0,000

Level of significance: 0,05

Correlation coefficient: 0,709

- From the result obtained in the correlation coefficient, it can be evidenced that the Strategic Management and Project Success variables are related in a positive way, for which it can be concluded that the success of a project is perceived by the surveyed via how the objectives of the company align with those of the project, thus generating value to the organization. In other words, the success of a 
software project is largely explained by the alignment of the project with the organizational strategy [23].

- The result obtained in the $p$ value index is lower than the level of significance defined for the regression [27]. This implies that the null hypothesis must be rejected and therefore hypothesis 1 is accepted. This leads us to conclude that the success of a software project is partly explained by the level of alignment of the objectives of the project and the strategy of the client company.

\subsubsection{Relation between the Performance of the Project Team and Project Success}

Research Hypothesis:

- H2. The Performance of the Project Team is decisive in the achievement of the objectives that are set for a software project.

- H0. The Performance of the Project Team is NOT determinant in the achievement of the objectives that are set for a software project.

Relation between variables:

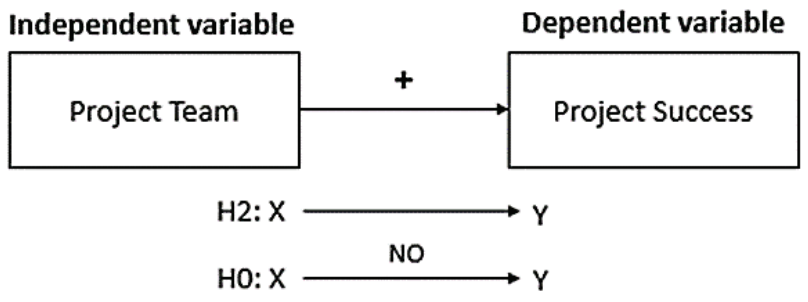

Figure 3 Project Team and Project Success (Prepared by the authors)

Results obtained:

For the treatment of the data, we developed the necessary regressions on the data that was obtained by means of the factorial analysis, for the Project Team and Project Success variables, in order to determine their level of correlation. The results obtained were:

$p$ value: 0,000

Level of significance: 0,05

Correlation coefficient: 0,721

Analysis of results:

- The correlation coefficient shows a positive relation between the level of performance of the project team and the success of a software project. Since these are knowledge generation projects, a high acceptance by project teams with an excellent level of training and experience is perceived among the surveyed. That is, the success of a software project is explained, to a large extent, by the performance of people who are related to it.

- In the case of the $p$ value index, we obtained a result that is lower than the significance level, which leads us to conclude that the null hypothesis should be rejected, thus accepting hypothesis two.

\subsubsection{Relation between Risk Management and Project Success}

Research Hypothesis:

- H3. Properly managing the risks of a software project increases your probabilities of success.
- H0. Properly managing the risks of a software project DOES NOT increase the probabilities of success.

Relation between variables:

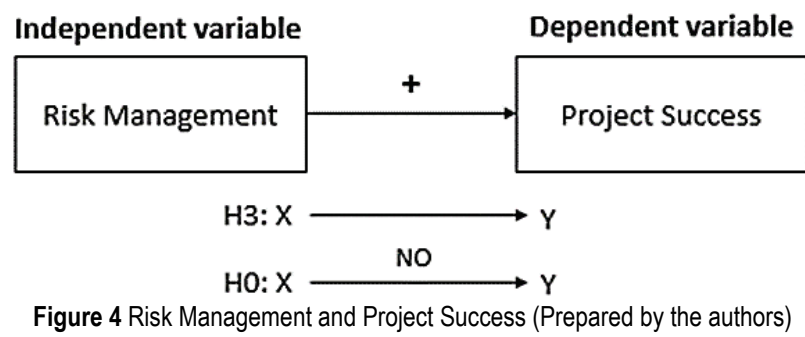

Results obtained:

Based on the results that were obtained in the regression, we present the following data for the correlation coefficient, the $\mathrm{p}$ value index and the level of significance, in the Risk Management and Project Success variables.

\section{$p$ value: 0,001}

Level of significance: 0,05

Correlation coefficient: 0,787

Analysis of results:

- In the case of Risk Management, a positive correlation index that explains the success of a software project is observed. It can be concluded that by increasing the evaluation and control over the variables that can affect the project, a greater probability of success can be achieved.

- On the other hand, the result of $p$ value leads us to conclude that the null hypothesis should be rejected, because its result is lower than the level of significance defined for the regression. Therefore, hypothesis 3 is approved; leading us to infer that this variable has a positive impact on the success of the software projects being undertaken.

\subsubsection{Relation between Knowledge Management and Project Success}

Research Hypothesis:

- H4. Software projects that rely on lessons that have been learned in the past are more likely to be successful.

- H0. Software projects that rely on lessons that have been learned in the past are NO more likely to be successful.

Relation between variables:

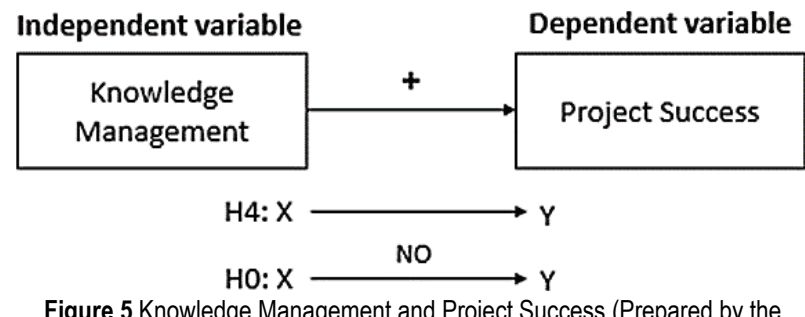

Figure 5 Knowledge Management and Project Success (Prepared by the authors)

Results obtained: 
In order to validate the research hypothesis 4 , the results of the regression that was applied on the data obtained from the factor analysis for the Knowledge Management and Project Success variables are presented, in order to determine their level of correlation.

$p$ value: 0,000

Level of significance: 0,05

Correlation coefficient: 0,776

Analysis of results:

- Like the previous variables, a very good level of correlation between Knowledge Management and the success of a software project is evidenced. From the data collected in the survey, it can be inferred that most of the people who were interviewed value the lessons learned in the past as an input to undertake future projects. Reducing uncertainty means that fewer mistakes are made, thus increasing the possibilities of project success

- In the case of the result of the $p$ value, the result obtained was lower than the level of significance, as well as the other hypotheses already evaluated, the null hypothesis is rejected and hypothesis 4 is approved, concluding that the lessons learned are highly treasured by software project managers.

\subsubsection{Relation between Project Planning and Project Success}

Research Hypothesis:

- H5. Properly managing the scope, time, and costs of a software project will positively impact its success.

- H0. Properly managing the scope, time, and costs of a software project WILL NOT impact its success positively.

Relation between variables:

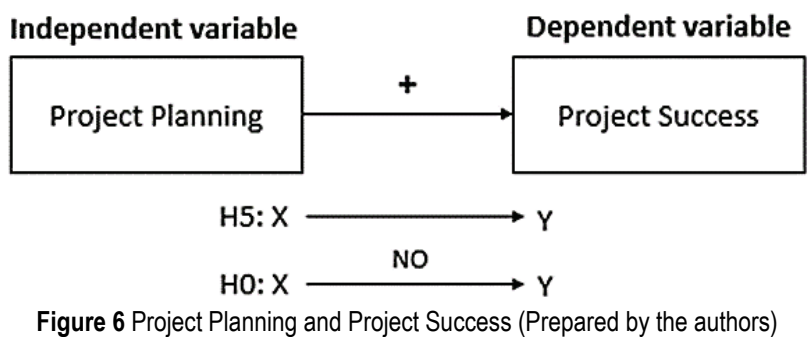

Results obtained:

For the treatment of the data, we developed the necessary regressions on the data that was obtained by means of the factorial analysis, for the Planning Management and Project Success variables, in order to determine their level of correlation. The results obtained were:

$p$ value: 0,000

Level of significance: 0,05

Correlation coefficient: 0,723

Analysis of results:

- As for the relation that there is between planning management and project success, a positive correlation index is observed, which leads us to infer that the control over the triple restriction: scope, time and cost is a determinant and basic task for the project managers who were surveyed.

- For $p$ value, we obtained a result that is lower than the significance level, therefore, the null hypothesis is rejected and hypothesis 5 is approved, concluding that the correct planning of a project increases its probability of success.

\section{CONCLUSIONS}

- The proposed research hypotheses were statistically validated. It can be said that a software project is more likely to be successful when there is a correct alignment between the strategy of the client company and the project objectives, an efficient work team, proper risk and knowledge management, and a detailed planning of the activities that must be carried out.

- The results of this research work are relevant to the extent that they propose to concentrate the efforts on managing the software projects on the five variables that were selected, which facilitates the process of administration and control of the project, more so when the implementation of methodologies recognized at global level sometimes become complex, costly or inadaptable to the local context.

- Analyzing a project only from the perspective of the triple restriction is not enough to consider it successful, it is also very important to take some points into account: the value that the project is generating to the company, if the result meets the needs of the stakeholders and therefore, it gives a solution to the problem posed, or allows to obtain advantages to face the identified opportunity.

- Project management methodologies provide a systemic and structured view to organize work. However, despite the different tools that have been developed to be used in this discipline, soft skills such as leadership, communication, teamwork and decision making become central axes to increase the probability of success of the project.

- Identifying in detail the risks that can affect the project is an alternative management that minimizes the impact by anticipating the problems. Under this premise, project managers should devote resources and effort to properly manage situations that may lead to deviations beyond the permitted standards. Answer the questions: ¿what can go wrong? or $¿$ what would happen?

- The main difference between traditional and agile methodologies is observed in the rigidity of its structures. On the one hand, traditional methodologies privilege detailed planning to ensure the quality of the final product, while agile methodologies open space for changes in the scheming regardless of the variations in time and cost. It can be concluded that traditional methodologies focus on protecting planning integrity to ensure product quality, while agile methodologies focus on customer satisfaction based on project flexibility.

- The six agile methodologies herein reviewed agree on the importance of client participation throughout the project. Some say that the customer must be a member of the project team, since the quality of the final product depends on it. 
- The impact of the project on the organizational strategy is a key indicator for measuring the success of the project, and it is emphasized by both tendencies. Although it is true that from the point of view of the operation, the triple restriction can mark whether a project is successful or not, it also highlights the contribution that the project makes to the fulfilment of the strategic objectives of the company. It can be affirmed that the success of a project is relative and depends to a great extent on the expectations that the interested parties may have towards the final result.

- For a business strategy to be successful, it must be supported by a clear and solid organizational structure. Software projects are aligned with business strategy to the extent that they generate products that allow the optimization of organizational structures.

- The active participation of a key user in the project strengthens the relationship between the client company and the development company, favouring the correct identification of needs and the achievement of results.

- Ensuring the quality of projects through the identification and control of generic risks reduces the probability of making mistakes and improves customer satisfaction against the project result.

\section{REFERENCES}

[1] Blanchard, K., Randolph, W. A., \& Carlos, J. P. (2002). Empowerment: 3 Claves para lograr que el proceso de facultar a los empleados funcione en su empresa. México: Editorial McGraw Hill.

[2] Arguello, W. (2007). MDS 360 - Metodología de Desarrollo de Software. Revista Española de Innovación, Calidad e Ingeniería del Software - REICIS, 14-24.

[3] Baccarini, D. (1999). The logical framework method for defining project success. Project Management Journal, 30(4), 25-32. https://doi.org/10.1177/875697289903000405

[4] Linberg, K. (2000). Software developer perceptions about software project failure: a case study. The Journal of Systems and Software, 49(2), 177-192.

[5] Canós, J., Letelier, P., \& Penadés, M. C. (2003). Metodologías Ágiles en el Desarrollo de Software. Metodologías Ágiles en el Desarrollo de Software, 1(10), 18. Valencia España: Universidad Politécnica de Valencia.

[6] Artto, K., Kujala, J., \& Martinsou, M. (2005). Business Project. Helsinki, Finlandia: Department of Industrial Engineering, Helsinki University of Technology.

[7] Charvat, J. (2003). Project management methodologies: selecting, implementing, and supporting methodologies and processes for projects. Canadá: John Wiley \& Sons, Inc.

[8] Chrissis, M., Konrad, M., \& Shrum, S. (2011). CMMI for Development: Guidelines for Process Integration and Product Improvement. Boston: SEI Series in Software Engineering.

[9] Project Management Institute - PMI. (2012). Project Management Body of Knowledge (PMBOK Guide). Newtown Square, PA: Project Management Institute INC.

[10] ICONTEC. (2012). Orientación sobre la gestión de proyectos. Bogotá, Colombia: ICONTEC. ISO 21500:2012.

[11] International Project Management Association - IPMA. (2016). Project Management Guideline. IPMA. Ginebra, Suiza: IPMA.

[12] Goldratt, E. (1997). Critical chain: a business novel. Great Barrington, MA: The North River Press.
[13] Khurana, H. \& Sohal, J. (2011). Agile: The necessitate of contemporary software developers. International Journal of Engineering Science \& Technology, 22-34.

[14] Highsmith, J. (2000). Adaptive Software Development: A Collaborative Approach to Managing Complex Systems. New York, NY: Dorset House Publishing Co.

[15] Joskowicz, J. (2008). Reglas y prácticas en extreme programming. Vigo, España: Universidad de Vigo - España.

[16] Navarro, A., Fernández, D., \& Morales, J. (2013). Revisión de metodologías ágiles para el desarrollo de software. Prospect, 11(2), 30-39. https://doi.org/10.15665/rp.v11i2.36

[17] Poppendieck, M. \& Poppendieck, T. (2003). Lean Software Development: An Agile Toolkit. Eden Prairie. Boston, MA: Addison-Wesley Professional.

[18] Aubry, M., Hobbs, B., \& Thuillier, D. (2007). A new framework for understanding organizational project management through the PMO. International Journal of Project Management, 25(4), 328-336. https://doi.org/10.1016/j.jpproman.2007.01.004

[19] Sapag, N. (2007). Gestión de proyectos. Ciudad de México, México: Pearson.

[20] Kerzner, H. (2003). Project Management: A Systems Approach to Planning, Scheduling, and Controlling. New York, NY: Wiley.

[21] Fortune, J. \& White, D. (2006). Framing of project critical success factors by a systems model. International Journal of Project Management, 24(1), 53-65. https://doi.org/10.1016/j.jpproman.2005.07.004

[22] Bryde, D. (2000). Project management: uses, structures, systems and influences. Liverpool JM University. Doctoral dissertation. Liverpool.

[23] Nedovic-Budic, Z. \& Pinto, J. (2000). Understanding inter organizational GIS activities: A conceptual framework. URISA Journal, 11(1), 53-64.

[24] Larson, E. \& Gray, C. (2011). Project Management: the managerial process. Oregon, EEUU: Mc Graw Hill.

[25] Pávez, A. (2000). Modelo de implantación de gestión del conocimiento y tecnologías de la información para la generación de ventajas competitivas. 1-25.

[26] Miranda, J. J. (2004). El desafio de la Gerencia de Proyectos. Bogotá: Universidad del Rosario.

[27] Caralt, J. S., López, M. C., \& del Barrio, T. (2002). Modelo de regresión lineal múltiple: especificación, estimación y contraste. New York, EEUU: UOC.

\section{Contact information:}

Nelson MORENO, PhD in Organizational Management

Professor-Researcher

Universidad EAN

Bogotá, Colombia

nmoreno@universidadean.edu.co

Fernando SALAZAR, PhD in Logistics and Supply Chain Management Professor-Researche

Editor-Director Journal of Accounting Papers

Director Research Group Integration and Accounting Context Colciencias

Department of Accounting Sciences,

Faculty of Economic and Administrative Sciences,

Pontificia Universidad Javeriana,

Carrera 7 No 40B-36, Jorge Hoyos Vázquez Building, S.J. (20), 6th Floor Bogotá, Colombia

Tel: (57-1)3208320 Ext 5139

salazar.fernando@javeriana.edu.co

Sandra DELGADO, Master in Administration

Professor-Researcher

Universidad EAN

Bogotá, Colombia

smdelgado@universidadean.edu.co 